\title{
A BIBLIOTERAPIA NO TRATAMENTO DE ENFERMOS HOSPITALIZADOS
}

\author{
Geovana Mascarenhas do Nascimento \\ Dulcinea Sarmento Rosemberg
}

\begin{abstract}
Resumo
Discorre sobre a biblioterapia como auxiliar no processo de tratamento de enfermos hospitalizados. Destaca a importância do método biblioterapêutico e suas técnicas como ferramentas no auxílio ao tratamento de doenças que acometem o corpo e o espírito do ser humano. Neste contexto, constata que a biblioterapia pode conduzir à pacificação das emoções e tornar-se coadjuvante do processo de cura de pessoas hospitalizadas. Diante dos resultados obtidos e apresentados na literatura, há preocupação também com a temática no que se refere, especialmente, à necessidade de referendá-la para além do uso da leitura de textos literários como única técnica biblioterápica em uma sociedade em que o diálogo pode ser inspirado usando-se múltiplas e variadas formas de expressão.
\end{abstract}

\section{Palavras-Chave}

Biblioterapia; Tratamento em ambientes hospitalares; Método biblioterapêutico em hospitais.

\section{INTRODUÇÃO}

Biblioterapia é um termo derivado das palavras latinas livro e tratamento. Biblio refere-se à raiz etimológica de palavras usadas para designar todo tipo de material bibliográfico ou de leitura; e terapia significa cura ou restabelecimento. Por ser as- sim, em 1941 o termo foi definido pelo Dicionário Dorland's Ilustrated Medical Dictionary, como sendo: "o emprego de livros e a leitura deles no tratamento de doença nervosa”, mas nas Idades Antiga e Média já se fazia referência ao uso terapêutico da leitura (apud ALVES, 1982). No Egito Antigo, cujo povo era voltado para a espirituali- 
dade e as bibliotecas situavam-se em templos denominados de "Casas da Vida", eram consideradas espaços de conhecimento e de espiritualidade. O Faraó Ramsés II, por exemplo, solicitou que fosse colocada no frontispício de sua biblioteca a frase: "Remédios para a Alma" (ALVES, 1982). Em Roma também não era diferente, o romano Aulus Cornelius Celsus, por sua vez, associou a leitura ao tratamento médico, ao recomendar a leitura e discussão das obras de grandes oradores como recurso terapêutico no desenvolvimento da capacidade crítica do paciente (ORSINI, 1982). O povo grego igualmente associava os livros ao tratamento médico e espiritual. Na Idade Média, período marcado pela religiosidade, em que as bibliotecas eram localizadas nos mosteiros e templos, também havia a preocupação de referendar a literatura religiosa como adequada à cura e salvação da alma. Como cita ALVES (1982) na Biblioteca da Abadia de São Gall encontrava-se a inscrição: "Tesouros dos remédios da alma".

Assim, a função terapêutica da leitura originada na espiritualidade e religiosidade dos povos antigos resiste ao tempo e chega aos nossos dias. Há registros de que no Século XIII, mais precisamente em 1272, o Hospital Al Mansur, recomendava aos pacientes a leitura de trechos especialmente escolhidos, e contidos no Alcorão como parte do tratamento médico (MARCINKO,
1989). No século XIX a leitura passou a ser adotada no tratamento de doentes mentais, e foi ainda recomendada aos doentes em geral, pelo pesquisador norte-americano Benjamin Rusch, que em 1810 indicava a leitura como apoio à psicoterapia para as pessoas portadoras de conflitos, tais como depressão, medos ou fobias, e também para a melhoria da qualidade de vida dos idosos (ALVES, 1982).

O estudo da biblioterapia começou a ganhar ênfase na década de 1930, quando “destacam-se as Biblioterapeutas Isabel Du Boir e Emma T. Foremam, principalmente esta última, que insistiu para que a biblioterapia fosse vista e estudada como uma ciência e não como arte" (ORSINI apud FERREIRA, 2003, p. 37).

Atualmente, a biblioterapia é utilizada em vários campos da área de Saúde e também na área de Educação. Na Psiquiatria, é usada desde 1800 e na Psicologia passou a ser um auxiliar importante por volta de 1946; a relação entre psique humana e literatura foi apontada por Vygostky em seus estudos sobre a infância. Em Medicina é largamente utilizada como um fator importante de ajuda, principalmente no tratamento de pessoas submetidas a longos períodos de internação. Na área de Biblioteconomia há indícios de sua aplicação por bibliotecários no início do Século $X X$, mais precisamente durante a Primeira Guerra Mundial (1914-1918), quando utilizaram a 
leitura como auxílio na recuperação dos pacientes feridos (PINTO, 2005).

\section{A BIBLIOTERAPIA NO ESPAÇO E TEMPOS VIVIDOS}

Os fundamentos teóricos da biblioterapia são apresentados e discutidos por vários estudiosos, entre os quais destacam-se QUAKNIN (1996), CALDIN (2001) FERREIRA (2003), RIBEIRO (2006). Para esses autores, principalmente, QUAKNIN (1996), a tese central da biblioterapia é que o ser humano, como criação contínua e em movimento constante, encontra suas forças no processo narrativo-interpretativo da atividade da leitura. Tem, portanto, na interpretação do texto uma possibilidade de terapia, uma vez que essa se realiza por meio da constante movimentação entre o indivíduo e o texto. Assim, tem-se em conta que a biblioterapia é uma forma de comunicação, que propicia trabalhar o emocional do paciente em parceria com o tratamento tradicional. Conforme expõem os autores, um indivíduo ao ler um texto entende as situações vividas por cada personagem, passa a identificar as situações que são apresentadas na história e pode a partir disso correlacionar e compreender os próprios problemas, criando para si laços e traços que tenha encontrado no texto identificando-se com a história lida. Acredita-se que um pensamento reflexivo estimulado pela leitura seja um início para a ação, ca- racterizando os objetivos da cura e prevenção.

Esse postulado leva à conceituação da biblioterapia como sendo um processo interativo que resulta em uma integração bem sucedida de valores e ações, a partir do uso de materiais selecionados como terapêuticos. Concebida assim, a biblioterapia se apropria do conceito ampliado de leitura, que inclui como suporte todo tipo de material, inclusive, os não convencionais. A leitura, portanto, vai além da pura decodificação de signos lingüísticos, pois se torna uma prática voltada para o social. Trata-se de práticas leitoras, em que são utilizados textos verbais e não verbais para atuarem como apoio no processo de tratamento de pessoas acometidas por enfermidades originadas por perdas provocadas por morte ou separação, violências, vícios, entre outras que sejam apresentadas pelos indivíduos em qualquer fase da sua vida.

Em suma, a biblioterapia é um método que consiste na dinamização e na ativação da linguagem. As palavras não são neutras. A linguagem metafórica conduz o homem para além de si, ele se torna outro, livre no pensamento e na ação (CALDIN, 2001). Durante o processo, a linguagem está sempre em movimento, nunca é estática, e isso é fundamental na aplicação da biblioterapia, em que o diálogo é o eixo norteador do tratamento. Ainda de acordo 
com a autora o processo biblioterapêutico permite ao indivíduo:

- verificar que há solução para o seu problema;

- verificar suas emoções em paralelo às emoções do outro;

- ajudar a pensar na experiência vicária em termos humanos e não materiais;

- proporcionar informações necessárias para a solução dos problemas;

- encarar a sua situação de maneira realista subsidiando-o na condução da ação.

A biblioterapia não deve ser confundida com a psicoterapia, pois enquanto esta se caracteriza pelo encontro entre o paciente e o terapeuta (CALDIN, 2001), na primeira o encontro é entre o texto e o seu leitor. Ou seja, o texto desempenha o papel de terapeuta enquanto o biblioterapeuta é aquele que conduz o processo mediático em que as formas orais, visuais, gestuais, auditivas, corporais, entre outras, podem estar presentes. Assim, a função do biblioterapeuta é potencializar o diálogo entre 0 autor e o seu leitor visando facilitar o processo de tratamento. Dessa maneira, a biblioterapia pode ser considerada como a terapia do diálogo. Como aborda Shrodes (1949), o diálogo é apropriado ao tratamento de várias patologias, entre elas, o autismo, a esquizofrenia ou a paranóia. Ao adotar o diálogo embasado na leitura de um texto literário, cada comentário, cada palavra, cada ação disparada a partir do texto lido, torna-se de fundamental importância, pois acrescenta valores, idéias, opiniões e sentimentos em quem ouve e quem fala.

Entretanto, para que o diálogo seja eficiente do ponto de vista curativo ou preventivo é necessário que o trabalho biblioterapêutico seja previamente estruturado e planejado tendo como base as especificidades do(s) caso(s) a ser (em) tratado(s). Esse procedimento implica na escolha das técnicas, bem como na seleção dos materiais adequados ao perfil de cada paciente/caso. O perfil do paciente deve incluir dados acerca de seus interesses, grau de conhecimento, estado de saúde e grau de possibilidade de desenvolvimento das atividades que serão propostas durante o procedimento. Cada indivíduo tem uma característica que lhe é peculiar e o profissional deve estar atento a essas diferenças, fazendo com que os métodos e técnicas escolhidas no processo sejam realmente eficazes. Assim, é possível dizer que tanto quanto a formação adequada dos profissionais envolvidos com o método biblioterapêutico torna-se imprescindível como também acertar na correspondência entre a técnica e o caso a ser tratado terapeuticamente. Isso implica em afirmar que, para que a técnica seja desenvolvida com sucesso é preciso escolher o material a ela pertinente, que pode ser uma música, um 
vídeo, um fantoche, um texto literário, entre outros. O importante é propiciar ao paciente a interpretação e a compreensão de que é possível operar sobre o real e produzir uma nova vida.

Em síntese, Ferreira (2003, p. 43) estabelece entre as diretrizes básicas para o desenvolvimento do processo biblioterapêutico a capacitação profissional; formação de grupos homogêneos; preparação do material de acordo com o perfil dos pacientes; utilização de materiais conhecidos pelo profissional; além de procurar evitar materiais que causem constrangimento ou deprimam o usuário, ou seja, deve-se proporcionar ao paciente um estado de empatia com relação ao material usado, buscando produzir valores positivos e o aumento de sua auto-estima. Cada caso deve ser analisado, pois a seleção de um método, técnica ou material não vale como regra para todos.

Neste cenário, vale ressaltar que a biblioterapia não deve ser tomada como sinônimo único do uso terapêutico da leitura. A leitura de textos literários pelo próprio paciente é apenas uma das técnicas biblioterapêuticas, visto que hoje elas são múltiplas e variadas e devem ser utilizadas para deflagrar o diálogo, base do processo biblioterapêutico, ou seja, entram em cena o teatro e a música que podem ser realizadas pelo profissional. Aliás, em um país como o Brasil em que, conforme dados do
IBGE, 13,6\% das pessoas são analfabetas, o fazer bibliotecário deve ser redimensionado e as práticas ativas do profissional devem visar e ampliar as chances de leitura de mundo das pessoas hospitalizadas. Daí, a necessidade de trabalhar com outras formas de expressão como o teatro, a música, a oralidade, a imagem.

Independentemente da técnica a ser aplicada, Caldin (2001), utilizando a abordagem psicanalítica de Freud, aponta quatro fases a serem vivenciadas durante a aplicação da biblioterapia. A primeira delas é a fase da identificação do paciente com o personagem, é como se permitisse ao indivíduo assimilar algo do que está acontecendo. Na segunda fase, destaca-se a projeção em que o indivíduo transfere para o outro (pessoa ou objeto) as idéias e sentimentos que podem ser familiares a ele, por exemplo: uma teoria pessoal de vida. $\mathrm{Na}$ terceira fase, está a catarse, há o envolvimento emocional do leitor na história, levando-o à descarga de idéias e emoções, que se libertam do inconsciente para o consciente. Essa técnica foi desenvolvida por Freud na terapia psicanalítica. Na quarta e última fase, deve ocorrer o insight. $\mathrm{O}$ paciente, neste instante, parte para a discussão construtiva de seus sentimentos e de suas idéias. O conteúdo do que foi lido, ouvido, visto, ou apresentado é elaborado por ele de modo a favorecer uma mudança de comportamento. 
Parafraseando Quaknin (1996), podemos dizer que quaisquer que sejam as técnicas biblioterápicas, estas se conduzem pela interpretação do que está sendo apresentado, dividindo-se o trabalho terapêutico em dois momentos: explicação e aplicação. A explicação evidencia a estrutura do conteúdo, o funcionamento interno, portanto, uma interpretação objetiva. A aplicação, por sua vez, é o momento em que ocorre, por parte do paciente, a produção de sentido, a apropriação subjetiva; o sujeito correlaciona o conteúdo com o próprio sofrimento, experiência, caso vivido, etc. Diante dessa perspectiva, o autor define o processo biblioterapêutico como um movimento de metamorfose, uma prática, uma vivência que pode levar a alteraçãoalteridade, a um ser diferente, a novas configurações possíveis do pensamento e da ação. Sendo assim, pode ser entendida como uma ferramenta para a semiologia e a terapêutica, favorecendo a humanização das mesmas e ajudando na recuperação dos pacientes (CALDIN; BUENO, 2002). A interação entre a semiologia, a terapêutica e a biblioterapia proporciona aos pacientes hospitalizados momentos de conhecimento de sua existência, bem como e análise de seus sentimentos. $O$ processo biblioterapêutico propicia a edificação do aprendizado e colabora na formação e na transformação do indivíduo. A leitura é um exercício sócio-cultural que só se alcança quan- do há capacidade do leitor em atribuir sentido ao texto lido.

Segundo a Comissão Interinstitucional Nacional de Avaliação do Ensino Médico (CINAEM) (2000) a semiologia é a arte técnica de conversar e examinar o paciente que tem como objetivo descobrir, contextualizando e conhecendo a pessoa, para que se chegue a um diagnóstico. A semiótica pode estar relacionada diretamente com a biblioterapia que está fundamentada no diálogo. Implica, dessa maneira, em significar o estado de saúde ou de doença por uma única causa, geralmente biológica. Já Caldin (2002), tratando a biblioterapia com uma fundamentação teórica estruturada, apresenta as metodologias adotadas neste processo, mencionando a catarse como parte fundamental do processo, em que ocorre o apaziguamento das emoções, pois define a catarse como a justa medida dos sentimentos. A autora também cita o riso, a identificação, a introjeção e a projeção destacando a suas finalidades terapêuticas. A identificação é um dos mecanismos psicológicos centrais na obra de Freud, em que explica o termo projeção como diferentes manifestações da psicologia e da patológia. A introjeção possui então um papel fundamental no estudo da aversão mundo exterior/ego.

Nesta dimensão de análise a biblioterapia é tida como um método terapêutico a ser aplicado utilizando-se técnicas plurais 
para ativação do diálogo entre o paciente e ele mesmo; com o grupo em que está inserido, com a equipe ou o biblioterapeuta que está conduzindo o processo. Para além desse entendimento binário do sujeito, fruto do paradigma moderno de ciência (sujeito $x$ objeto, mundo interno $x$ mundo externo, objetivação x subjetivação), está a possibilidade de investir no método biblioterapêutico considerando o indivíduo a partir da mistura de vidas que por ele passaram e que, portanto, o constituem, um entrecruzamento de sentimentos e de expressões diversas: o que viu, o que ouviu, o que sentiu, o que rejeitou, o que percebeu, o que leu, o que desejou, o que faz, o que deixou de fazer (BARROS, 2006). Assim, é preciso acreditar na possibilidade do diálogo como produtor de sentido, de expansão da vida, de produção de potência da vida a ser vivida e de outros modos de subjetivar.

\section{A BIBLIOTERAPIA E O FAZER} INSTITUINTE - UM PROCESSO DINÂMICO

À luz do exposto, apresentam-se algumas experiências que corroboram o entendimento da biblioterapia como um processo que pode instituir novas formas de ser e estar no mundo, principalmente, quando desenvolvida com pessoas enfermas em tratamento no ambiente hospitalar, que se encontram afastadas do convívio familiar, fragilizadas pela condição imposta pela doença.
Seitz (2000), em dissertação de mestrado, apresentou um estudo objetivando experienciar a prática biblioterapêutica com pacientes internados em uma clínica médica, em que verificou um processo de hospitalização menos doloroso e agressivo. Foram utilizados vários tipos de fontes de informação, como textos literários, artigos de jornais e de revistas. Constatou-se que por meio da leitura os pacientes puderam compartilhar suas emoções, dúvidas e angústias, bem como vivenciarem momentos de alegria no grupo, cuja vida estava sendo tecida coletivamente por fios que os uniam rumo à cura.

Em 2002, Caldin relata um caso vivenciado com crianças internadas no Hospital Universitário da Universidade Federal de Santa Catarina, cujo objetivo estava em buscar humanizar o processo de tratamento das crianças. Assim, foram realizadas leituras de textos literários, na modalidade individual e em grupo, e atividades lúdicas tendo a música e a dramatização como recursos biblioterapêuticos. Constatou-se que as crianças puderam se ver nos personagens das histórias possibilitando uma introjeção e uma introspecção por parte das mesmas. Percebeu-se que passaram a entender as suas limitações e os seus problemas, encarando-os de maneira positiva.

Esses autores notaram que, ao ser desenvolvida, a biblioterapia também foi salutar tanto para os pacientes quanto para 
os familiares e acompanhantes, diminuindo, inclusive, o grau de estresse, que normalmente acometem as pessoas em ambiente hospitalar. Principalmente para crianças, a internação não é fácil, haja vista que são arrancadas de sua rotina de brincadeiras, do seu mundo lúdico e encantado, e passam a viver em um ambiente, de certa maneira, "frio" porque diferente daquele de outrora. A propósito, como menciona a autora, as crianças envolvidas com o trabalho biblioterápico, desenvolveram um grande interesse pelos livros e, conseqüentemente foram estimuladas para a leitura.

Em outra experiência, Caldin (2004) também com crianças hospitalizadas no Hospital Universitário de Santa Catarina, desta vez trabalhando com a arte da contação de histórias ("Seu Feliz", "A Casa Sonolenta", "Lúcia-já-vou-indo", "Chapeuzinho Vermelho", "Chapeuzinho Amarelo" e "Maria-vai-com-as-outras"), concluiu que houve uma sensibilidade individual e ao mesmo tempo coletiva, uma vez que a mesma história pôde ser apresentada e trabalhada com diversos pacientes. Notouse que a leitura de textos literários estimulou o intelecto, mas também a emoção, objeto importante a ser enfrentado. Considerando que da catarse espera-se uma resposta emocional, as histórias infantis levaram as crianças a potencializarem a sua capacidade, conforme verificou a autora, diminuindo a dor e o sofrimento. Assim sendo, destaca-se que o conto infantil desenvolveu a sensibilidade estética, pois permitiu à criança sonhar mesmo estando em processo de hospitalização. A identificação da criança com o personagem da história, mesmo estando fragilizada e sem condições de locomoção física, transportou-a para o mundo da imaginação, fazendo com que participasse da aventura que Ihe foi apresentada. É o universo da fantasia na alma infantil.

Caldin (2004) considera os contos de fadas como terapêuticos, porque podem oportunizar vitórias mesmo diante dos obstáculos, e principalmente por alimentarem a esperança de cura, haja vista que o final feliz das histórias age como uma mola propulsora de alívio, esperança e fé a partir da identificação das crianças com o personagem. Uma história é um presente de amor. Crianças doentes e crianças sadias necessitam igualmente de amor. Porém, vale lembrar que histórias com finais tristes também podem significar alívio e conforto, pois ao se deparar com o personagem o paciente não se sente mais só com seu problema.

Uma outra vivência, o "Projeto Biblioteca Viva", criado pelo Centro Universitário do Norte Paulista em 2004, também promove a biblioterapia como recurso terapêutico coadjuvante no tratamento de pacientes internados. O Projeto mantém minibibliotecas em centros de saúde e hospi- 
tais, visando oferecer aos pacientes, acompanhantes e familiares recursos de leitura para ocupar o tempo ocioso e contribuir para o bem-estar mental dos pacientes envolvidos em tratamentos de saúde. Para isso, investe em atividades diversificadas. A biblioteca itinerante chega por meio do ônibus-biblioteca, que circula pelos bairros oferecendo: brinquedoteca, caixas-estantes circulantes, que são minibibliotecas armazenadas em caixas e carrinhos-biblioteca, que passam nos centros de saúde e hospitais.

Em síntese, essas experiências permitem evidenciar que o diálogo pode ser uma fonte de restituição de vida em momentos de fragilidade, angústia, desespero ou descrença. O poder da palavra pode significar para alguém uma mudança, uma nova esperança. Terapia entende-se como o poder mais vasto da palavra, ela vem acompanhada de carinho, atenção e cura. Para cuidar da saúde é necessário, muitas vezes, rever condutas diante de hábitos $\mathrm{e}$ costumes, e adotar uma postura permanente de fazer da vida uma "obra de arte", uma estética da existência, como dizia Foucault (apud BARROS, 2006), ou seja, ver a vida com mais arte, com mais carinho para, só então, por intermédio da palavra cuidar do outro. Essa análise está voltada principalmente para as questões humanas. Quando o indivíduo encontra-se acometido por alguma enfermidade, os valores huma- nos podem ser despertados para novas formas de vida em toda a sua expansão de criação.

Atualmente, entre tantas atividades e estratégias desenvolvidas nos hospitais, que têm tornado a internação um processo mais humanizado e menos agressivo ao ser humano a biblioterapia, vem a ser um mecanismo de promoção da vida, uma vez que metodologicamente, propicia respostas, mesmo que provisórias, para questionamentos provenientes do momento de reclusão humana. Como enganar a dor? Como driblar o sofrimento? Como derrubar barreiras? Como adquirir força de vontade para continuar? Muitas vezes os pacientes encontram essas respostas em si, no outro, nas histórias narradas, nas experiências (com) partilhadas, nas situações humoradas criadas, por exemplo, pelos "Doutores da Alegria" ${ }^{1}$, que provocam o riso e a gargalhada, na realidade encenada pelos grupos teatrais, na fé praticada pelos grupos religiosos, considerados mensageiros da promessa, da esperança de cura. Todos esses "fios tecem" uma rede que pode reabilitar a saúde, a potência de vida a ser vivida em toda a sua plenitude.

\footnotetext{
${ }^{1}$ Organização de utilidade pública sem fins lucrativos, pioneira no Brasil em levar alegria para as crianças e os adolescentes hospitalizados.
} 


\section{CONCLUSÃO}

Diante disto, considera-se a biblioterapia um método coadjuvante da cura pelo diálogo ativado pelo uso de diferentes tipos de materiais informacionais, que podem auxiliar tanto no tratamento quanto na prevenção dos males do físico e da mente. Portanto, destaca-se a importância da seleção acertada desses materiais, cuidandose de sua correspondência com o caso em foco, e a necessidade de se constituir equipes multidisciplinares, cujos saberes e fazeres sejam dirigidos ao processo de tratamento.

As equipes devem ser compostas, conforme as especificidades, por assistentes sociais, bibliotecários, educadores, enfermeiros, médicos, psicólogos, entre outros profissionais. No que se refere aos bibliotecários, os autores que ajudaram nesta reflexão enfatizam o campo como um segmento de trabalho social em Biblioteconomia a ser explorado por esses profissionais da informação. No Espírito Santo, de modo especial, em nível acadêmico, verifica-se que os alunos do Curso de Biblioteconomia da UFES, têm despertado para a relevância do estudo e trabalho na área de biblioterapia, o que é evidenciado pelos trabalhos de conclusão de cursos por eles realizados.

Inicialmente, foi elaborada por Gurgel (2003) uma revisão de literatura sobre o assunto apresentando os conceitos, os objetivos e as técnicas empregadas pelos autores que se ocupam do assunto. Por sua vez Oliveira (2003) interessou-se por relatar uma experiência biblioterapêutica realizada em uma escola capixaba tendo como sujeitos, crianças portadoras de Síndrome de Down, enfatizando a parceria proveitosa que pode surgir daí com a Educação Especial. Em estudo de campo intitulado "Biblioterapia: um recurso terapêutico coadjuvante no processo de ressocialização das detentas da Penitenciária Estadual Feminina", Heringer (2004), demonstrou a necessidade de o Estado adotar um programa terapêutico de lazer para as internas, a fim de combater a ociosidade, o estresse e o sofrimento provocados pela solidão que acometem o ambiente prisional. Além desses, também Celegari e Ronconi (2004) demonstraram seu interesse pela área de biblioterapia produzindo um estudo sobre o tema e as suas possibilidades e potencialidades de melhorar da qualidade de vida dos idosos asilados.

Em todos os trabalhos mencionados registrou-se que a biblioterapia pode estimular o intelecto dos pacientes, mas principalmente o seu emocional. Por essa, entre outras características do trabalho biblioterapêutico, evidencia-se a necessidade de os profissionais desejosos de atuarem na área buscarem uma formação especializada de modo a atenderem as especificidades da mesma. 
Por último, mas não menos importante, observa-se que a biblioterapia deve ser vista como um complemento a outras terapias e não apenas como única possibilidade de tratamento psicológico. De acordo com os autores citados e com os relatos das experiências expostos neste artigo, podemos afirmar que a biblioterapia alivia as tensões, angústias e medos, desenvolve a imaginação e ajuda no crescimento emocional e psicológico do paciente.

\section{REFERÊNCIAS}

ALVES, Maria Helena Hess. A aplicação da biblioterapia no processo de reintegração social. Revista Brasileira de Biblioteconomia e Documentação, São Paulo, v.15, n.1/2, p.54-61, jan./jun., 1982.

BARROS, M. E. B. de. Modos de trabalhar, modos de subjetivar. Vitória: UFES, 2006. Palestra proferida para profissionais das áreas de saúde, educação, serviço social e administração em 7 jul. 2007.

CALDIN, C. F; BUENO, S. B. A aplicação da biblioterapia em crianças enfermas. Revista ACB: Biblioteconomia em Santa Catarina, Florianópolis. v. 7, n. 1, p.157-169, 2002. Disponível em: $<$ http://www.encontros-bibli.ufsc.br> Acesso em: 26 mai. 2005.

CALDIN, C. F. A leitura como função terapêutica: biblioterapia. Encontros Bibli: Revista de Biblioteconomia e Ciência da Informação, Florianópolis, n.12, dez. 2001. Disponível em: <http//www.encontrosbibli.ufsc.br> Acesso em: 26 mai. 2005.

A aplicabilidade terapêutica de textos literários para crianças. Encontros Bibli: Revista Eletrônica de Biblioteconomia e Ciência da Informação, Florianópolis, n.18, out. 2004. Disponível em:

$<$ http://dici.ibict.br> Acesso em: 20 mai. 2005.

Biblioterapia para crianças internadas no hospital universitário da UFSC. Encontros Bibli: Revista de Biblioteconomia e Ciência da Informação, Florianópolis, n.14, out. 2002. Disponível em: <http//www.encontros-bibli.ufsc.br> Acesso em: 17 jun. 2005.

CELEGARI, R. L. P.; RONCONI, M. N. A utilização da biblioterapia: uma possibilidade de melhoria da qualidade de vida dos idosos. 2004. (Graduação em Biblioteconomia) - Departamento de Ciências da Informação, Universidade Federal do Espírito Santo, Vitória, 2004.

\section{COMISSÃO INTERINSTITUCIONAL} NACIONAL DE AVALIAÇÃO DO ENSINO MÉDICO. Proposta. In: _. Preparando a transformação da educação médica brasileira: projeto CINAEM III fase: relatório 1999-2000. Pelotas: UFPel, 2000.

FERREIRA, D. T. Biblioterapia: Uma prática para o desenvolvimento pessoal. Educação Temática Digital, São Paulo, v. 4, n. 2, p. 35-47, jun. 2003. Disponível em: <http://www.bibli.fae.unicamp.br> Acesso em: 25 jan. 2004.

GURGEL. Biblioterapia: uma revisão de literatura. 2003. Trabalho de Conclusão de Curso (Graduação em Biblioteconomia) Departamento de Ciências da Informação, Universidade Federal do Espírito Santo, Vitória, 2003.

HERINGER, Maria das Graças de Luna Arruda. Biblioterapia: um recurso terapêutico como coadjuvante no processo de ressocialização das detentas da Penitenciária Estadual Feminina. 2004. Trabalho de Conclusão de Curso (Graduação em Biblioteconomia) - Departamento de Ciências da Informação, Universidade Federal do Espírito Santo, Vitória, 2004.

INSTITUTO BRASILEIRO DE GEOGRAFIA E ESTAATÍSTICA. Educação 
no Brasil. Disponível em:

<http//www.ibge.gov.br> Acesso em: 26 set. 2005.

MARCINKO, Stephanie. Bibliotherapy pratical applications with disabled individuals. Current Studies in Librarianship, v.13, n.1/2, p. 1-5, Spring/Fall, 1989.

OLIVEIRA, M. da P. O uso da biblioterapia na educação especial: um relato de caso. 2003. Trabalho de Conclusão de Curso (Graduação em Biblioteconomia) - Departamento de Ciências da Informação, Universidade Federal do Espírito Santo, Vitória, 2003.

ORSINI, Maria Stella. O uso da literatura para fins terapêuticos: biblioterapia. Comunicações e Artes, n. 11, p.139-149, 1982.

PARDINI, M. A. biblioterapia: um encontro perfeito entre o bibliotecário, o livro e o leitor no processo de cura através da leitura: Estamos preparados para essa realidade? In: SEMINÁRIO NACIONAL DE BIBLIOTECAS UNIVERSITÁRIAS, 12. 2002, Recife. Anais... Recife: UFPE, 2002.

PINTO, V. B. A biblioterapia como campo de atuação para o bibliotecário. Transinformação, Campinas, n. 17, p. 31-43, jan./abr. 2005.

QUAKNIN, M-A. Biblioterapia. São Paulo: Loyola, 1996.

RIBEIRO, G. Biblioterapia: uma proposta para adolescentes internados em enfermarias de hospitais públicos. Revista Digital de Biblioteconomia e Ciência da Informação, Campinas, v. 3, n. 2, p. 112-126, jan./jun.2006. Disponível em:

http://server01.bc.unicamp.br> Acesso em: 18 jun.2005.

SEITZ, E. M. Biblioterapia: uma experiência com pacientes internados em clínica médica. 2000. 79f. Dissertação (Mestrado em Engenharia de Produção) Universidade Federal de Santa Catarina, Florianópolis, 2000.
SHRODES, Caroline. Bibliotherapy: a theoretical and clinical-experimental study. 1949. 344f. Dissertation (Doctor of Philosophy in Education) - University of California. Berketey.

SILVA, P. V. P. da.; LUCAS, E. R. de O. Terapia pela literatura: biblioterapia para crianças. Disponível em:

<http//www.crb7.org.br>. Acesso em: 25 maio 2006.

Geovana Mascarenhas do Nascimento Bacharel em Biblioteconomia (UFES) geomasc@yahoo.com.br

Dulcinea Sarmento Rosemberg

Professora do Departamento de Ciências da Informação (UFES)

dsrosemberg@globo.com

\section{Title}

The bibliotherapy for the treatment of hospitalized people

\section{Abstract}

This work considers the bibliotherapy as an auxiliary for the treatment process of ill patients. It points out the importance of the bibliotherapeutic as a method for the human's body and soul diseases treatment. In this context, it emphasizes that the bibliotherapy may lead to emotions' peace and to become a support in the patients' recovery. The results achieved by this study and the results presented in the literature, allows to recognize that there is also a preoccupation concerning this thematic, specially about the importance of the confirmation of this technique beyond the reading of literary works, outstanding its importance in a society where the dialog may be inspired by multiples and a by variety of expressions forms usage. 


\section{Keywords}

Bibliotherapy - Treatment in Hospital Environment; Bibliotherapeutic Method in Hospitals

\section{Título}

La Biblioterapia en el tratamiento de enfermos hospitalizados

\section{Palabras Clave}

Biblioterapia; Tratamiento en ambientes hospitalarios; Método biblioterapéutico en hospitales.

\section{Resumen}

Discurre sobre la biblioterapia como coadyuvante en el proceso de tratamiento de enfermos hospitalizados. Destaca la importancia del método biblioterapéutico y sus técnicas como herramientas en el auxilio del tratamiento de enfermedades que acometen el cuerpo y el espíritu del ser humano. En este contexto, constata que la $\mathrm{Bi}-$ blioterapia puede conducir a la pacificación de las emociones y se vuelve coadyuvante en el proceso de cura de personas hospitalizadas. Delante de los resultados obtenidos y presentados en la literatura existe, también, la preocupación con la temática en lo que se refiere, especialmente, a la necesidad de refrendarla para más allá del uso de la lectura de textos literarios como única técnica biblioterápica en una sociedad en que el diálogo puede ser inspirado usando múltiplas y variadas formas de expresión.

Recebido em: 09.04.2007

Aceito em: 17.06.2007 